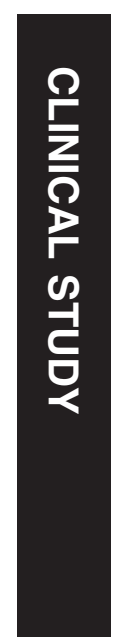

\section{The effect of erythropoietin on the severity of retinopathy of prematurity}

Y Kandasamy ${ }^{1,2}$, P Kumar ${ }^{1}$ and L Hartley ${ }^{3}$

Introduction
${ }^{1}$ Department of

Neonatology, The Townsville Hospital, Douglas,

Queensland, Australia

${ }^{2}$ Mothers and Babies Research Centre, Hunter Medical Research Institute, John Hunter Hospital, Locked Bag 1, Hunter Region Mail Centre, Newcastle, New South Wales, Australia

${ }^{3}$ Department of Optometry and Vision Science, The University of Melbourne, Melbourne, Victoria, Australia

Correspondence: Y Kandasamy, Department of Neonatology, The Townsville Hospital, 100 Angus Smith Drive, Douglas, Queensland 4814, Australia

Tel: +61 7 44332989;

Fax: +61 744332981 .

E-mail: dryoga1@

bigpond.com

Received: 29 October 2013 Accepted in revised form: 25 March 2014 Published online: 25 April 2014

\begin{abstract}
Aims Exogenous human erythropoietin (EPO) artificially synthesised through recombinant DNA technology (rHuEPO) is currently used as a substitute for blood transfusion in preterm and low birth weight neonates. The objective of this study is to determine whether the use of rHuEPO is associated with an increased severity of retinopathy of prematurity (ROP) in preterm neonates.

Method This retrospective review studies neonates who were admitted to a tertiary perinatal unit and screened for ROP during the 10-year period from January 2003 to December 2012.

Results During the 10-year period, 688 preterm neonates underwent ROP screening, with 198 identified as having ROP. The incidence of stage 1 ROP was $51.5 \%$ (102/198), followed by $35.9 \%(71 / 198)$ for stage 2 , and $12.6 \%(25 / 198)$ for stage 3 and greater. Plus disease was seen in 14 neonates $(7.1 \%)$. Treatment (laser photocoagulation) was administered in $64 \%$ of neonates $(16 / 25)$ with stage 3 of the disease and above because of progression to threshold ROP. Twenty-six $(13 \%)$ of the neonates received $\mathrm{rHuEPO}$ treatment. There were no statistically significant differences in birth weight $\mathbf{9 1 0 . 4}$ vs $885 \mathrm{~g} ; \boldsymbol{P}=\mathbf{0 . 7 1}$ ), gestational age (26.5 vs 25.8 weeks; $P=0.09$ ), and duration of ventilation (512 vs $501.4 \mathrm{~h} ; P=0.92$ ) between neonates who did not receive $\mathrm{rHuEPO}$ compared with those who were treated with rHuEPO. Multivariate regression analysis showed that the use of EPO was associated with increased severity of ROP.

Conclusions EPO therapy appears to increase the risk of development and worsening of ROP.

Eye (2014) 28, 814-818; doi:10.1038/eye.2014.95; published online 25 April 2014
\end{abstract}

More than 15 million neonates are born preterm $(<37$ weeks gestation) annually and the numbers are increasing. ${ }^{1}$ With improved neonatal survival in many developing countries, the number of neonates diagnosed with blindness as a result of retinopathy of prematurity (ROP) is expected to exceed 50000 cases annually. ${ }^{2}$ The pathophysiology of ROP is complex and it occurs when an immature retina responds to life-saving measures instituted to sustain the life of a significantly preterm neonate. Our current understanding of this condition indicates that this process is initiated by the interruption of retinal development with hyperoxia and undernutrition, which is then followed by a pathological proliferative phase. ${ }^{3}$ Insulin-like growth factor-1, vascular endothelial growth factor (VEGF), and erythropoietin (EPO) have been identified as the key molecular mediators in the pathogenesis of ROP. ${ }^{3}$

Exogenous human EPO artificially synthesised through recombinant DNA technology ( $\mathrm{rHuEPO}$ ) is currently used as a substitute for blood transfusion in preterm and low birth weight neonates. ${ }^{4}$ The side effects of rHuEPO are a matter of intense research, with animal studies ${ }^{5,6}$ and human data showing conflicting findings linking $\mathrm{rHuEPO}$ with ROP. A study by Schneider et $\mathrm{al}^{7}$ concluded that the use of rHuEPO for prevention or treatment of anaemia of prematurity causes a significant reduction in the number of transfusions but does not increase the incidence of severe ROP. A systematic review by Aher and Ohlsson ${ }^{4}$ concluded that early initiation of EPO (initiated at $<8$ days of age) causes a statistically significant increased risk of ROP. In the last decade, the rHuEPO molecule has been further enhanced by increasing its carbohydrate content beyond that found naturally (hyperglycosylated 
rHuEPO analogues), thus enhancing its biological activity. ${ }^{8}$ These agents are also known as erythropoiesis-stimulating agents and, apart from their increased biological activity, have a longer half-life. In a recently published randomised control trial using such an agent (Darbepoetin alfa) in a cohort of 102 preterm neonates, transfusion was avoided in $\sim 50 \%$ of the neonates enrolled in this study. ${ }^{9}$ More importantly, there was no significant difference in the incidence of ROP between the study and control groups. As there continues to be a debate regarding the association between exogenous EPO therapy and ROP, we carried out a study to determine whether the use of EPO increased the severity of ROP in preterm neonates.

\section{Materials and methods}

This retrospective study was performed in the Department of Neonatology, Townsville Hospital, North Queensland, which is a tertiary perinatal centre responsible for a region with more than 10000 annual births. There are $\sim 2000$ births in the hospital per year. The neonatal department has $\sim 800$ admissions per year, with one-third out-born neonates. ROP examination was carried out on preterm neonates $<32$ weeks old and/or neonates born with a birth weight $<1500 \mathrm{~g}$. Older neonates were also included for ROP assessment if they were very ill. The International classification for ROP is used and ROP Stage 3 or worse is classified as severe ROP. ${ }^{10}$ Since 2006, all examinations were carried out using a retinal camera (RetCam II, Clarity Medical Systems, Pleasanton, CA, USA). Examinations were carried out under sedation and with adequate pain relief. ${ }^{11}$ Images of neonates needing treatment were reviewed remotely by a paediatric ophthalmologist before treatment. ${ }^{12}$ For this study, newborn neonates admitted to the department from January 2003 to December 2012 and needing ROP examination were identified from the department's perinatal electronic database and medical records. Neonatal and maternal clinical information was then extracted for analysis. The decision to administer this rHuEPO was at the discretion of the neonatal paediatrician on duty, and the neonates who had received this medication during their stay were also identified. The dosage used was $200 \mathrm{U} / \mathrm{kg}$, administered subcutaneously three times a week. The Townsville Health District Human Research Ethics Committee approved the study.

\section{Statistical analysis}

The results were expressed as the mean \pm SD for continuous, normally distributed data and as the median (interquartile range, IQR) for continuous, non-normally distributed data. Comparisons of the means of normally distributed data were made using paired/unpaired $t$-tests, and the Mann-Whitney test was used for nonnormally distributed data. A $P$-value $<0.05$ was considered statistically significant. A multiple regression model was used to determine the relation of the studied risk factors to the severity of ROP. Statistical analyses were performed using MedCalc Version 12.3 (MedCalc Software, Mariakerke, Belgium).

\section{Results}

During the 10-year period from January 2003 to December 2012, 688 preterm neonates underwent ROP screening, with 198 identified as having ROP. Their characteristics are summarised in Table 1. Neonates with ROP when compared with neonates without ROP $(n=490)$ were significantly smaller at birth $(970 \pm 320 \mathrm{~g}$ vs $1354 \pm 687 \mathrm{~g} ; P=<0.001)$ and were more premature (26.4 \pm 2.2 weeks vs $29.7 \pm 3.8 ; P<0.001)$. There were statistically significant differences in the proportion of neonates receiving EPO between both groups. These neonates were predominantly extremely preterm with a median gestation age of 26.3 (IQR 25-27.5) weeks. Among these, 18 neonates were $\leq 24$ weeks (9.1\%), 142 were born between 24 and 28 weeks $(71.7 \%)$, and 37 were born between 28 and 32 weeks (18.7\%) of gestation. The median birth weight was $865 \mathrm{~g}$ (IQR 712-1022). The birth weight of three neonates was $\leq 500 \mathrm{~g}(1.5 \%)$, 141 were 500-1000 g (71.1\%), and 51 were 1000-1500 g (25.7\%). Only two neonates had a birth weight between 1500 and $2000 \mathrm{~g}(1 \%)$ and one had a birth weight of $4000 \mathrm{~g}(0.5 \%)$. The majority of these neonates required endotracheal ventilation $(93.4 \%, n=185)$ because of respiratory distress syndrome, with most also requiring surfactant therapy $(77.8 \%, n=154)$ and supplemental oxygen therapy $(n=178,89.9 \%)$. The incidence of stage 1 ROP was $51.5 \%$

Table 1 Demographic characteristics and respiratory data of study population (neonates with ROP)

\begin{tabular}{lc}
\hline Variable & \\
\hline Male gender & $104(52.5 \%)$ \\
Median birth weight $(\mathrm{g})$ & 865 (IQR 712-1022) \\
Median gestational age (weeks) & 26.3 (IQR 25-27.5) \\
Apgar 1 min & 5.5 (IQR 4-7) \\
Apgar 5 min & 8 (IQR 6-9) \\
No. of neonates who received surfactant & $154(77.8 \%)$ \\
No. of doses of surfactant received & 2 (IQR 1-2.0) \\
No. of neonates needing endotracheal ventilation & $185(93.4 \%)$ \\
Maximum FiO $\mathrm{O}_{2}$ (\%) while ventilated & 52 (IQR 35-79) \\
Endotracheal ventilation duration (h) & 391.5 (IQR 70.7-726.1) \\
No. of neonates needing supplemental $\mathrm{O}_{2}$ & $178(89.9 \%)$ \\
Supplemental $\mathrm{O}_{2}$ duration (h) & 1423 (IQR 184-2278) \\
No. of neonates who received postnatal steroids & $85(42.9 \%)$ \\
Duration of postnatal steroids (days) & 14 (IQR 7-27) \\
\hline
\end{tabular}

Abbreviations: $\mathrm{FiO}_{2}$, fraction of inspired oxygen concentration; IQR, interquartile range. 
(102/198), followed by $35.9 \%$ (71/198) for stage 2 , and $12.6 \%$ (25/198) for stage 3 and greater. In addition, plus disease was also observed in 14 neonates $(7.1 \%)$.

Treatment via laser photocoagulation was administered in $64 \%$ of the neonates $(16 / 25)$ with stage 3 of the disease and above because of progression to threshold ROP. Only one neonate with Stage 3 ROP received medical therapy with Bevacizumab (an antivascular endothelial growth factor (VEGF) monoclonal antibody). There was bilateral involvement of eyes in $86.9 \%(172 / 198)$ of the neonates and unilateral involvement in $13.1 \%(26 / 198)$ of the neonates.

Twenty-six (13\%) of the neonates received $\mathrm{rHuEPO}$ treatment. The mean post-menstrual age when EPO was commenced was $33.3 \pm 3.1$ weeks. There was no statistically significant difference in birth weight (910.4 vs $885 \mathrm{~g} ; P=0.71$ ), gestational age (26.5 vs 25.8 weeks; $P=0.09$ ), and duration of ventilation (512 vs $501.4 \mathrm{~h}$; $P=0.92$ ) between neonates who did not receive $\mathrm{rHuEPO}$ compared with those who were treated with $\mathrm{rHuEPO}$. Using the Mann-Whitney test, we compared the severity of ROP staging between neonates who received $\mathrm{rHuEPO}$ and those who did not, finding that neonates who received $\mathrm{rHuEPO}$ had significantly more severe ROP $(P=0.007)$. The median total (cumulative) dose of EPO received by each neonate was 2740 (478-3097) units. There were no significant difference in cumulative EPO dosage received by neonates with severe ROP (Grade 3 or worse) when compared with those with milder form of ROP (Grades 1 and 2) (2750 (1032-5830) vs 3200 (1620-5000) units; $P=0.94)$. Multivariate regression analysis was carried out to determine the risk factors associated with severe ROP (Table 2). The use of EPO was associated with increased severity of ROP $(P=0.004)$.

\section{Discussion}

From our study, using multivariate regression, we found that rHuEPO use is associated with increased severity of ROP. However, our study did not show any dose-response relationship. It is very likely that EPO contributes to the development of ROP through mechanisms yet to be fully understood at this point in time. Most of the understanding regarding the pathogenesis of this condition is based on animal models. Human preterm neonates, similar to the newborns of other mammalian species, have incomplete retinal vascularisation at birth, and oxygen can be used to induce artificial retinal microvascular changes. ${ }^{13}$ Contrary to preterm neonates, the retinal developmental stage at birth of these animals is appropriate for their species. Hence, findings from research on animals, while valuable, are not $100 \%$ applicable to humans.

In humans, EPO is produced in the foetal liver and later in the adult kidney. Its main function is erythrocyte maturation and differentiation. ${ }^{14}$ Lubetzky et al ${ }^{15}$ have shown that neonates with increased absolute neonatal nucleated red blood cells have an increased chance of developing ROP compared with match control and it is possible that $\mathrm{rHuEPO}$ contributes to ROP through increased erythropoiesis. Non-erythroid functions of EPO include neurotrophic, neuroprotection, ${ }^{16}$ and regulation of angiogenesis. ${ }^{17} \mathrm{EPO}$ is also essential for normal retinal development as evidenced by the presence of the EPO receptor in the region of active cell reproduction in the developing retina. ${ }^{18}$ In response to hypoxia/ischaemia, there is increased expression of EPO receptor. ${ }^{19}$ Although VEGF is a key mediator of retinal angiogenesis, VEGF inhibition in itself was found to be insufficient to halt retinal neovascularization. ${ }^{20}$ From a study carried out in adults with diabetic proliferative retinopathy, it was concluded that EPO is a potent ischaemia-induced angiogenic factor that acts independently of VEGF during retinal angiogenesis. ${ }^{20}$ It is proposed that EPO may have a similar role in ROP. ${ }^{14}$

Patel et $a l^{21}$ show that in the foetal retina EPO mRNA increased with increasing gestational age, in both vitreous and serum. EPO concentrations were significantly greater in vitreous than in serum and these differences were maintained throughout pregnancy. The investigators proposed that changes in EPO production following preterm delivery might affect

Table 2 Multiple regression analysis of risk factors for severe ROP

\begin{tabular}{|c|c|c|c|}
\hline Independent variables & $\beta$ coefficient & $S E$ & $\mathrm{P}$ \\
\hline Birth weight $(\mathrm{g})$ & 0.00006 & 0.0004 & 0.88 \\
\hline Gestational age (weeks) & -0.06 & 0.05 & 0.18 \\
\hline Duration of mechanical ventilation (h) & 0.0002 & 0.0002 & 0.34 \\
\hline Maximum partial pressure oxygen in arterial blood $(\mathrm{mm} \mathrm{Hg})$ & 0.0004 & 0.002 & 0.83 \\
\hline Sepsis (positive blood culture) & -0.09 & 0.13 & 0.52 \\
\hline Duration of supplemental oxygen (h) & -0.000006 & 0.00007 & 0.94 \\
\hline Number of packed cell transfusions & 0.04 & 0.04 & 0.26 \\
\hline Received $\mathrm{rHuEPO}$ & 0.50 & 0.17 & 0.004 \\
\hline
\end{tabular}

Abbreviations: rHuEPO, exogenous human erythropoietin synthesised through recombinant DNA technology; ROP, retinopathy of prematurity. Final model: (F-ratio $=3.13, P=0.003$ ). 
retinal vascular development. ${ }^{21}$ Chen $e t a l^{22}$ investigated the effects of EPO on retinal neovascularisation in a mouse model of retinopathy. The investigators found that in the initial phase of ROP, the local levels of EPO were suppressed. The administration of exogenous EPO prevented vessel dropout, hypoxia-induced neuronal apoptosis, and subsequent hypoxia-induced neovascularization. The investigators found that retinal EPOs were elevated during the retinal neovascularisation phase. Exogenous EPO administration during the later phase enhanced pathological and abnormal neovascularisation.

Contrary to the animal model, a systematic review on neonates receiving $\mathrm{rHuEPO}$ concluded that EPO initiated at less than 8 days of (postnatal) age led to a significant increase in the risk of ROP. ${ }^{4}$ In another study, the risk of developing ROP was found to be higher in neonates who received $>20$ days of RHuEPO ( $\sim 7$ weeks of treatment). ${ }^{23}$ It is currently unknown whether the effect of this treatment is dosage-dependant. The dose we used is similar to another published study. ${ }^{9}$

The main limitation of this study is that it is a retrospective study. Furthermore, the mode of retinal examination changed in 2006 once the department acquired the retinal camera. The examinations were also carried out by different ophthalmologists over the years, and this is another limitation of the study as we are unable to determine the interoperator variability. The use of rHuEPO is based on individual clinician preference and we recognise this to be another limitation of this study. Nevertheless, we believe that this finding is of importance as rHuEPO has a crucial role in the field of neonatal medicine. In recent years, both animal studies $^{24,25}$ and human clinical trials ${ }^{16,26}$ have demonstrated that the use of $\mathrm{rHuEPO}$ reduces the severity of perinatal asphyxia, thus reducing the risk of disability in neonates. There is evidence to suggest that EPO has a protective effect on the developing kidney, ${ }^{27}$ in the treatment of periventricular leukomalacia in neonates, ${ }^{28}$ and in the reduction in ventilatory support time in preterm neonates. ${ }^{29}$ We believe that the use of rHuEPO and its newer analogues in neonatal medicine are very likely to increase.More studies with these newer drugs are needed in the future to determine the impact on neonatal retinal health.

\section{Conclusions}

EPO therapy appears to increase the risk of development and worsening of ROP. However, the mechanistic link between ROP and EPO is not yet fully understood. Clinicians treating preterm neonates should inform parents regarding the possible side effects of this treatment, which should be used with caution.
Summary

What was known before

- The number of premature babies with retinopathy of prematurity (ROP) is expected to increase.

- Erythropoietin (EPO) is increasingly being used in neonatal medicine.

- The currently available research shows conflicting results with regards to complications associated with the use of EPO.

What this study adds

- Erythropoietin therapy appears to increase the risk of development and worsening of ROP.

\section{Conflict of interest}

The authors declare no conflict of interest.

\section{Acknowledgements}

We thank the Department of Ophthalmology, The Townsville Hospital.

\section{References}

1 Chang HH, Larson J, Blencowe H, Spong CY, Howson CP, Cairns-Smith $\mathrm{S}$ et al. Preventing preterm births: analysis of trends and potential reductions with interventions in 39 countries with very high human development index. Lancet 2013; 381(9862): 223-234.

2 Gilbert C. Retinopathy of prematurity: a global perspective of the epidemics, population of babies at risk and implications for control. Early Hum Dev 2008; 84(2): 77-82.

3 Smith LE, Hard AL, Hellstrom A. The biology of retinopathy of prematurity: how knowledge of pathogenesis guides treatment. Clin Perinatol 2013; 40(2): 201-214.

4 Aher SM, Ohlsson A. Early versus late erythropoietin for preventing red blood cell transfusion in preterm and/or low birth weight infants. Cochrane Database Syst Rev 2012; 10: CD004865.

5 Slusarski JD, McPherson RJ, Wallace GN, Juul SE. High-dose erythropoietin does not exacerbate retinopathy of prematurity in rats. Pediatr Res 2009; 66(6): 625-630.

6 Mowat FM, Gonzalez F, Luhmann UF, Lange CA, Duran Y, Smith AJ et al. Endogenous erythropoietin protects neuroretinal function in ischemic retinopathy. Am J Pathol 2012; 180(4): 1726-1739.

7 Schneider JK, Gardner DK, Cordero L. Use of recombinant human erythropoietin and risk of severe retinopathy in extremely low-birth-weight infants. Pharmacotherapy 2008; 28(11): 1335-1340.

8 Egrie JC, Browne JK. Development and characterization of novel erythropoiesis stimulating protein (NESP). $\mathrm{Br}$ J Cancer 2001; 84(S1): 3-10.

9 Ohls RK, Christensen RD, Kamath-Rayne BD, Rosenberg A, Wiedmeier SE, Roohi M et al. A randomized, masked, placebo-controlled study of Darbepoetin Alfa in preterm infants. Pediatrics 2013; 132(1): e119-e127. 
10 ICCROP. The International Classification of Retinopathy of Prematurity revisited. Arch Ophthalmol 2005; 123(7): 991-999.

11 Kandasamy Y, Smith R, Wright IM, Hartley L. Pain relief for premature infants during ophthalmology assessment. J Aapos 2011; 15(3): 276-280.

12 Kandasamy Y, Smith R, Wright I, Hartley L. Use of digital retinal imaging in screening for retinopathy of prematurity. J Paediatr Child Health 2013; 49(1): E1-E5.

13 Hellstrom A, Smith LE, Dammann O. Retinopathy of prematurity. Lancet 2013; 382(9902): 1445-1457.

14 Romagnoli C, Tesfagabir MG, Giannantonio C, Papacci P. Erythropoietin and retinopathy of prematurity. Early Hum Dev 2011; 87(Suppl 1): S39-S42.

15 Lubetzky R, Stolovitch C, Dollberg S, Mimouni FB, Salomon M, Mandel D. Nucleated red blood cells in preterm infants with retinopathy of prematurity. Pediatrics 2005. 116(5): e619-e622.

16 Zhu C, Kang W, Xu F, Cheng X, Zhang Z, Jia L et al. Erythropoietin improved neurologic outcomes in newborns with hypoxic-ischemic encephalopathy. Pediatrics 2009; 124(2): e218-e226.

17 Jaquet K, Krause K, Tawakol-Khodai M, Geidel S, Kuck KH Erythropoietin and VEGF exhibit equal angiogenic potential. Microvasc Res 2002; 64(2): 326-333.

18 Juul SE, Yachnis AT, Christensen RD. Tissue distribution of erythropoietin and erythropoietin receptor in the developing human fetus. Early Hum Dev 1998; 52(3): 235-249.

19 Wang GL, Semenza GL. General involvement of hypoxiainducible factor 1 in transcriptional response to hypoxia. Proc Natl Acad Sci USA 1993; 90(9): 4304-4308.

20 Watanabe D, Suzuma K, Matsui S, Kurimoto M, Kiryu J, Kita $\mathrm{M}$ et al. Erythropoietin as a retinal angiogenic factor in proliferative diabetic retinopathy. N Engl J Med 2005; 353(8): 782-792.
21 Patel S, Rowe MJ, Winters SA, Ohls RK. Elevated erythropoietin mRNA and protein concentrations in the developing human eye. Pediatr Res 2008; 63(4): 394-397.

22 Chen J, Connor KM, Aderman CM, Smith LE. Erythropoietin deficiency decreases vascular stability in mice. J Clin Invest 2008; 118(2): 526-533.

23 Suk KK, Dunbar JA, Liu A, Daher NS, Leng CK, Leng JK et al. Human recombinant erythropoietin and the incidence of retinopathy of prematurity: a multiple regression model. J Aapos 2008; 12(3): 233-238.

24 Spasojevic SD, Stojanovic VD, Barisic NA, Doronjski AR, Zikic DR, Babovic SM. Neuroprotective effects of hypothermia and erythropoietin after perinatal asphyxia in newborn rats. J Matern Fetal Neonatal Med 2013; 26(15): 1506-1509.

25 Fan X, Heijnen CJ, van der KM, Groenendaal F, van Bel F. Beneficial effect of erythropoietin on sensorimotor function and white matter after hypoxia-ischemia in neonatal mice. Pediatr Res 2011; 69(1): 56-61.

26 Elmahdy H, El-Mashad AR, El-Bahrawy H, El-Gohary T, El-Barbary A, Aly H. Human recombinant erythropoietin in asphyxia neonatorum: pilot trial. Pediatrics 2010; 125(5): e1135-e1142.

27 Stojanovic V, Vuckovic N, Spasojevic S, Barisic N, Doronjski A, Zikic D. The influence of EPO and hypothermia on the kidneys of rats after perinatal asphyxia. Pediatr Nephrol 2012; 27(1): 139-144.

28 Wang T, Hu Y, Leach MK, Zhang L, Yang W, Jiang L et al. Erythropoietin-loaded oligochitosan nanoparticles for treatment of periventricular leukomalacia. Int J Pharm 2012; 422(1-2): 462-471.

29 Tempera A, Stival E, Piastra M, De Luca D, Ottaviano C, Tramontozzi $\mathrm{P}$ et al. Early erythropoietin influences both transfusion and ventilation need in very low birth weight infants. J Matern Fetal Neonatal Med 2011; 24(8): 1060-1064. 